\title{
The optimal minimum wage with regulatory uncertainty
}

\section{John Bennett ${ }^{1}$ iD | loana Chioveanu ${ }^{2}$}

\author{
${ }^{1}$ Department of Economics, Royal Holloway, \\ University of London \\ ${ }^{2}$ Department of Economics and Finance, Brunel \\ University \\ John Bennett, Department of Economics, Royal \\ Holloway, University of London, Egham, Sur- \\ rey, TW20 0EX,UK (j.bennett@rhul.ac.uk). \\ Ioana Chioveanu, Department of Economics \\ and Finance, Brunel University, Uxbridge UB8 \\ 3PH, UK (ioana.chioveanu@brunel.ac.uk). \\ We thank the Editor Rabah Amir, an associate \\ editor, and a referee for helpful comments. We \\ are also grateful for discussions with Volker \\ Hahn, Hartmut Lehmann, and participants at PET \\ 2015, Luxembourg, and the 10th Annual CEDI \\ Conference, Brunel University, 2015. The usual \\ disclaimer applies.
}

For two different regulatory standards, we examine the optimal minimum wage in a competitive labor market when the government is uncertain about supply and demand. Solutions are related to underlying supply and demand conditions, and to the extent of uncertainty and of rationing efficiency. With expected earnings maximization, greater uncertainty widens the range of parameter values for which a minimum wage should be set. With expected worker surplus maximization and sufficiently efficient rationing, a minimum wage should always be set. However, in both cases regulatory uncertainty may require a low minimum wage that may not bind in equilibrium.

\section{1 | INTRODUCTION}

A statutory minimum wage has been a common feature of public policy for many years, and currently operates in 26 out of 34 Organisation for Economic Co-operation and Development (OECD) member countries. Some parts of the United States also have "living wage" laws, setting a minimum wage above the federal minimum, while in the United Kingdom the living wage became a mandatory minimum for workers aged 25 or more in April 2016. Although the effects of a minimum wage remain controversial, changes in the sectoral mix of employment in developed economies associated with globalization and the recent recession have aroused new interest in its use. Many manufacturing and construction jobs have been lost that are unlikely to be replaced, whereas there has been an expansion of relatively low-paid work, such as in wholesale and retail trade, and accommodation and food services (OECD, 2015). ${ }^{1}$

When a minimum wage is introduced or raised some low-paid workers will receive higher wage rates, but there may be an overall negative impact on employment. Econometric evidence on this trade-off, which is reviewed by Neumark, Salas, and Wascher (2014), generally relates to the effects of small changes in a minimum wage. However, there is little evidence on the impact of larger changes, or for the introduction of a minimum wage. Thus, for example, a minimum

This is an open access article under the terms of the Creative Commons Attribution License, which permits use, distribution and reproduction in any medium, provided the original work is properly cited.

(C) 2017 The Authors Journal of Public Economic Theory Published by Wiley Periodicals, Inc.

${ }^{1}$ In the United States, the real wage for low-skill workers has declined for the last 30-40 years. Balart (2016) argues that this is largely the result of improved incentives to attend college, and he shows in a signaling model how this can adversely affect the average ability of the non-college educated. 
wage law was rejected by Switzerland in 2014, but introduced by Germany in 2015 and will come into operation in South Africa in 2018, in each case after years of heated debate about the size of the potential effects.

To capture some of the issues involved, we formulate a model in which the government may be imperfectly informed about supply and demand conditions when it sets the minimum wage (there is "regulatory uncertainty") whereas workers and firms have all the relevant information when employment takes place. ${ }^{2}$ This information structure may be interpreted to cover a situation where the minimum wage is fixed for a period over which a new set of market conditions may obtain. ${ }^{3}$ Alternatively, it could pertain to a single realization of a market in which both labor supply and labor demand are identically and independently distributed, and the government knows the parameters of the distributions. We use this formulation to derive the optimal level, if any, of the minimum wage for two different regulatory standards. For simplicity, we do not include in the analysis any other regulatory tools, such as an income tax.

We examine a perfectly competitive low-wage segment of the labor market. The assumption of perfect competition simplifies the analysis and has the advantage of being a particularly testing environment for a minimum wage, as it emphasizes the potential negative employment effects compared to when there is monopsony or search-andmatching in the labor market (see, e.g., Cahuc, Carcillo, \& Zylberberg, 2014). In this context, if the government's objective were to maximize expected welfare, no minimum wage would be set. However, the primary goal of minimumwage policy is to redistribute earnings to low-productivity workers (Freeman, 1996). This goal may be represented in various ways, but a simple and widely used formulation is in terms of the total earnings from the minimum wage (Sobel, 1999). We therefore derive the minimum wage that maximizes the expected earnings of minimum wage workers. $^{4}$

Nonetheless, as highlighted by L. Danziger (2009), the use of total earnings as a measure does not take into account workers' reservation wages, which reflect the value of unemployment benefits, leisure, and home production. If reservation wages are netted out, the goal instead becomes the maximization of "worker surplus," a term that was introduced by Marshall (1920) as a particular type of producer surplus. Insofar as reservation wages reflect alternative earnings, worker surplus may be more appropriate than total earnings as a measure of the financial benefit to workers earning the minimum wage. However, allowance for the value of leisure, a nonpecuniary element, makes it a measure of worker welfare. As an alternative to expected earnings maximization, we also analyze the expected worker surplusmaximizing minimum wage. ${ }^{5}$

When a minimum wage is set, if it binds efficient rationing of employment would require that the available work goes to individuals with the lowest reservation wages amongst those willing to work at that wage. However, the minimum wage may prevent some workers with lower reservation wages from competing by accepting relatively low wages. Job allocation may be inefficient, with personal contacts or prejudice playing a role. ${ }^{6}$ Direct evidence on inefficiency of employment rationing is sparse, though Luttmer (2007) finds that no such inefficiency is associated with the 1990-1991 rise in the U.S. federal minimum wage. Nonetheless, Luttmer cautions that this evidence relates to a small

\footnotetext{
2 Regulatory uncertainty stems from diverse sources, and is distinct from economic policy uncertainty, which relates to private agents' perceptions of potential government behavior. Even under settled economic conditions, a government will face some uncertainty about labor market conditions, but sectoral adjustments in economic activity may make the fine-tuning of minimum-wage policy more challenging, and, historically, periods of lower growth have coincided with higher levels of uncertainty (Bloom, 2014).

${ }^{3}$ In practice, most OECD countries review minimum wage levels every year, or nearly every year, though the federal minimum in the United States was unchanged from September 1997 to July 2007 (see OECD, 2015).

${ }^{4}$ Freeman argues that the effect of a minimum wage on total earnings in a competitive labor market may go in either direction and "[i]t is the balancing of risk against gain that makes a minimum so controversial" (Freeman, 1996, p. 639).

5 In practice governments have not specified explicit objective functions, and various further implications of a minimum wage have been considered. In the German debate these have included the fiscal impact, the effects on shadow activities, and the incentive to leave education (IZA, 2014). Other potential considerations include the effects on non-wage worker benefits (Schmitt, 2013) and on the welfare of the poor through increases in consumer prices (MaCurdy, 2015).

${ }^{6}$ Portugal and Cardoso (2006) and subsequent studies find that a higher minimum wage is associated with lower job turnover. One possible explanation is that, insofar as the higher minimum wage causes jobs to be kept by people who would move in a freer market, the rationing of jobs is inefficient. Also, resources may have been expended to reach the efficient outcome (e.g., search costs or waiting).
} 
increase in the minimum wage, and that inefficient allocation might nonetheless follow a large increase. We therefore parameterize rationing inefficiency in our analysis. ${ }^{7}$

We use simple quadratic formulations of aggregate reservation wages and nonlabor costs, so that labor supply and demand functions are linear. ${ }^{8}$ Throughout, we refer to labor supply in terms of the participation decision, but the model could instead be interpreted in terms of the hours of work decision. For simplicity, we consider regulatory uncertainty first over labor supply and then over labor demand, and we highlight some important differences of detail. We relate our solutions to the underlying supply and demand conditions and the degree of uncertainty the government faces. Also, for expected worker surplus maximization, the extent of rationing inefficiency matters, although it is not relevant for expected earnings maximization. For each objective, we show that, if uncertainty is great enough, the optimal minimum wage may or may not bind, depending on the resolution of the uncertainty.

In a textbook model with no uncertainty, to maximize total earnings the minimum wage is set such that the elasticity of labor demand is (minus) unity, provided this minimum wage binds. If it does not bind, a minimum wage should not be set. With uncertainty, our analysis of expected earnings maximization generalizes this result. We show that if the uncertainty is over labor supply, the optimal level of the minimum wage is still at unit-elastic labor demand, while if there is labor-demand uncertainty, the optimal minimum wage may be below the unit-elastic level for the mean labor demand curve. However, for each form of uncertainty, the side condition for setting any minimum wage is that the specified level binds for the minimum possible realization of the free market wage. This shows that the presence of regulatory uncertainty widens the range of parameter values for which a minimum wage should be set, and greater uncertainty widens this range.

When, instead, the objective is to maximize expected worker surplus, then for both labor supply uncertainty and labor demand uncertainty a minimum wage should always be set if the rationing of employment is efficient enough. If uncertainty is sufficiently small, the minimum wage should be set at a level that is sure to bind, and is above the level at which demand is unit-elastic. However, with greater uncertainty of either type, the minimum wage should be set at a lower level, and may or may not bind. By not setting a high minimum wage, large potential declines in employment are avoided; but by nonetheless setting one, though at a relatively low level, some protection is provided against ex post realizations of uncertainty that would result in a low free market wage. Inefficiency of rationing complements uncertainty over supply or demand, in that it reduces the critical amount of uncertainty at which the government chooses a minimum wage that may or may not bind, rather than one that is sure to bind.

However, if inefficiency is sufficiently great, no minimum wage should be set. All employment at the minimum wage gives a higher worker surplus than would be obtained in a free market. With inefficient rationing some of this employment is of workers who displace others who value employment more than themselves. If rationing is inefficient enough, the loss in expected worker surplus due to such inefficient reallocations, together with the lower expected labor demand, can fully offset the aggregate expected benefits from the employment at the higher wage. ${ }^{9}$

The effect of a minimum wage on worker surplus is analyzed by L. Danziger (2009). In his model, risk-averse workers face uncertainty about whether they will find a job, and the minimum wage that maximizes expected worker surplus is derived. Also, in an analysis of how a minimum wage may be set by bargaining, Boeri (2012) assumes that the government uses a welfare function that may include a higher weight on worker surplus (and this assumption is in effect made by Lee \& Saez, 2012; see below). Moreover, in labor market matching models, worker surplus-defined as the difference between the value of employment and the value of unemployment-has played a prominent role (see Jung \& Kuhn, 2014, for a recent example).

\footnotetext{
7 The effect of rationing inefficiency in the context of price ceilings is considered in several recent papers (see Glaeser \& Luttmer, 2003; Davis \& Kilian, 2011; Bulow \& Klemperer, 2012)

${ }^{8}$ The informational set-up in our model, together with quadratic approximations of cost and benefit, was first formulated by Weitzman (1974) to compare alternative regulatory instruments in a planned economy. The framework has since been adapted to various contexts, including monopoly regulation in a mixed economy and environmental policy, but it has not, to our knowledge, been applied to the labor market. For a recent formulation, see Schlee (2013).

${ }^{9}$ When there is no regulatory uncertainty the worker surplus-maximizing minimum wage is on the elastic (inelastic) part of the labor demand curve for high (low) enough rationing efficiency. Thus, it is greater (smaller) than the earnings-maximizing minimum wage for high (low) rationing efficiency. The comparison is not so clear-cut in the presence of regulatory uncertainty.
} 
The effect of a minimum wage used in combination with an income tax in a competitive economy is analyzed in a stream of papers beginning with Allen (1987) and Guesnerie and Roberts (1987). In these models, the case for setting any minimum wage is sensitive to the assumptions made. For example, in Allen's model, where labor supply is formulated as an hours of work decision, a minimum wage is of no value if optimal nonlinear income taxation is possible. However, with the restriction to optimal linear income taxation there is scope for welfare-enhancing redistribution through a minimum wage.

More recently, abstracting from the hours of work decision, Lee and Saez (2012) derive sufficient conditionsincluding efficiency of rationing and valuation by the government of redistribution toward low-wage workers-for it to be optimal to set a binding minimum wage, both with and without optimal taxes and transfers. Also, E. Danziger and Danziger (2015) show in a perfectly competitive model with hours choice by workers that a graduated minimum wage, in combination with an optimal nonlinear income tax, can provide a Pareto improvement over an optimal income tax alone. $^{10}$

Our framework may be applicable when optimal taxation is not feasible, and it deals with a different type of uncertainty. In the optimal tax literature, the asymmetric information relates to the government's lack of knowledge of individual characteristics, rather than to incomplete information about aggregate supply and demand. Nonetheless, when there is no uncertainty and the restriction of efficient rationing is made, our model is a linear equivalent of the Lee and Saez formulation without taxes and transfers.

Our analysis of the minimum wage is entirely static, disregarding, for example, the consequences for investment in human and physical capital. In the literature, endogenous growth models give potentially positive growth effects of a minimum wage. For example, Cahuc and Michel (1996) assume that the introduction of a minimum wage may increase the demand for skilled labor, so that more human capital is accumulated, promoting economic growth. Similarly, in the model of Askenazy (2003) a minimum wage causes an effort shift from production to R\&D, also stimulating growth. ${ }^{11}$ However, Economides and Moutos (2016) focus on the incentive to invest in physical capital rather than human capital, and show that the imposition of a minimum wage reduces the steady-state capital stock, employment, and after-tax incomes of employed workers.

In Section 2, we formulate our model. In Sections 3 and 4, we consider the cases of supply uncertainty and demand uncertainty, respectively, and Section 5 concludes. Proofs are given in the appendix.

\section{2 | THE MODEL}

Consider a competitive labor market in which the government may be uncertain of supply and demand. We assume that there is no uncertainty on the part of private agents. Workers' aggregated reservation wages for supplying / units of labor are given by $S(I, \phi)=(S+\phi) l+s l^{2} / 2$, where $s>0, S+\phi>0$. The government regards $\phi$ as a random variable with zero mean $(E(\phi)=0)$, distributed according to a continuous differentiable cumulative distribution function (c.d.f.). $F(\phi)$ defined on a closed interval $\left[\phi_{\min }, \phi_{\max }\right]$. The inverse supply of labor is

$$
\partial S(l, \phi) / \partial I=S+\phi+s l .
$$

Thus, $S+\phi$ is the lowest reservation wage in this market and $s$ is the labor supply slope. Producers' gross revenue, net of nonlabor costs, is given by $\mathcal{R}(I, \gamma)=(R+\gamma) I-r I^{2} / 2$, where $r>0, R+\gamma>0$. The government regards $\gamma$ as a random variable with zero mean $(E(\gamma)=0)$, distributed according to a continuous differentiable c.d.f. $G(\gamma)$ defined on a closed interval $\left[\gamma_{\min }, \gamma_{\max }\right]$. The inverse demand (marginal revenue product) for labor is

$$
\partial \mathcal{R}(l, \gamma) / \partial I=R+\gamma-r l
$$

with intercept $R+\gamma$ and slope $-r$.

10 The combination of a minimum wage and optimal taxation when the labor market is monopsonistic is analyzed by Cahuc and Laroque (2014).

11 See Fanti and Gori (2011) for a related model and a survey of this literature. 
The respective supply and demand functions for labor are therefore

$$
I^{s}(w, \phi)=(w-S-\phi) / s \quad \text { and } \quad I^{d}(w, \gamma)=(R+\gamma-w) / r
$$

where $w$ is the wage rate. The elasticity of demand for labor is (minus) unity at $w=R / 2$.

We assume that the two shocks $\phi$ and $\gamma$ are independent and that the hazard rates $F^{\prime}(\phi) /(1-F(\phi))$ and $G^{\prime}(\gamma) /(1-$ $\mathrm{G}(\gamma)$ ) are strictly increasing. ${ }^{12}$

The government chooses a minimum wage $\bar{w}$, which is announced to all private agents (firms and workers), who observe the realized values of $\phi$ and $\gamma$, and then generate labor supply and demand functions (1). Employment and production then take place. $\bar{w}$ is chosen to maximize the expectation of earnings $w l \equiv \Upsilon$ or worker surplus $w l-\mathcal{S}(l, \phi) \equiv$ $\Omega$. In practice, the time dimension for a minimum wage varies between countries (e.g., it is hourly in the United Kingdom, weekly in Malta, and monthly in Belgium). Our analysis can be interpreted in any of these units.

Denote the ex post-free market wage (where $\left.I^{s}(w)=l^{d}(w)\right)$ by $w^{*}(\phi, \gamma)$ and the corresponding employment level by $I^{*}(\phi, \gamma)$. Thus,

$$
w^{*}(\phi, \gamma)=[(S+\phi) r+(R+\gamma) s] /(r+s) \quad \text { and } \quad I^{*}(\phi, \gamma)=(R+\gamma-S-\phi) /(r+s)
$$

To ensure a well-defined equilibrium employment ex post, we assume that $R+\gamma_{\min }>S+\phi_{\max }$. But, before the demand and supply shocks $\phi$ and $\gamma$ are realized, the government views $w^{*}(\phi, \gamma)$ as a random variable with expected value

$$
w_{e}^{*}=(S r+R s) /(r+s)
$$

A minimum wage rate $\bar{W}$ may or may not bind. If it binds, that is, if $\bar{W}>W^{*}(\phi, \gamma)$, then employment $I(\bar{W})=I^{d}(\bar{W}, \gamma)$; if it does not bind, that is, if $\bar{W} \leq W^{*}(\phi, \gamma)$, the free-market equilibrium (2) obtains. Thus, if $I^{s}(\bar{W}, \phi)>I^{d}(\bar{W}, \gamma)$, employment is $I(\bar{W})=I^{d}(\bar{W}, \gamma)$; but if $I^{s}(\bar{W}, \phi) \leq I^{d}(\bar{W}, \gamma)$, employment is $I(\bar{W})=I^{*}(\phi, \gamma)$.

Given the distributions of $\phi$ and $\gamma$, three ranges for $\bar{W}$ may be distinguished. In the "high" range $\bar{w}$ is so high that it binds for all realizations of uncertainty. In the "low" range $\bar{w}$ is so low that it is nonbinding for all realizations of uncertainty. However, in the "middle" range $\bar{w}$ may or may not bind, depending on the value of $\phi$ (for stochastic supply) or $\gamma$ (for stochastic demand). We consider the minimum wage first for stochastic supply and then for stochastic demand. ${ }^{13}$ We examine each of these ranges as a potential location for the optimal value of $\bar{w}$, and we derive and compare the results for the two objective functions of the government.

If $\bar{W}>W^{*}(\phi, \gamma)$ there is an excess supply of labor at the minimum wage $\bar{w}$, so that $I=I^{d}(\bar{W}, \gamma)=(R+\gamma-\bar{w}) / r$ and employment is rationed. Insofar as rationing is inefficient, employment is not all allocated to the workers with the lowest reservation wages. We parameterize rationing efficiency for the case in which the government maximizes expected worker surplus by writing its objective function as a linear combination of the expected worker surplus for efficient rationing and for extreme inefficient rationing of employment among those who are willing to work at $\bar{w}$, with weights $\alpha$ and $1-\alpha$, respectively $(\alpha \in[0,1])$.

If work is allocated efficiently, that is, to the workers whose reservation wages are lowest, worker surplus is

$$
\begin{aligned}
& \bar{w} l^{d}(\bar{w}, \gamma)-\left[(S+\phi) l^{d}(\bar{w}, \gamma)+s\left(l^{d}(\bar{w}, \gamma)\right)^{2} / 2\right]= \\
& (R+\gamma-\bar{W})[2 r(\bar{w}-S-\phi)-s(R+\gamma-\bar{w})] / 2 r^{2} \equiv \Omega_{\alpha}\left(I^{d}(\bar{w}, \gamma), \phi\right) .
\end{aligned}
$$

Now suppose instead that $I^{d}(\bar{w}, \gamma)$ is allocated extremely inefficiently, that is, to those workers with the highest reservation wages among those willing to work at wage $\bar{W}$. Then, employment $l^{d}(\bar{W}, \gamma)=(R+\gamma-\bar{W}) / r$ is along the highest part of the supply curve below $\bar{W}$, that is, from $I^{s}(\bar{W}, \phi)-I^{d}(\bar{W}, \gamma)$ to $I^{s}(\bar{W}, \phi)$. At $I^{s}(\bar{W}, \phi)-I^{d}(\bar{W}, \gamma)$ worker surplus is

\footnotetext{
12 The strictly increasing hazard rate assumptions guarantee the single-peakedness of expected worker surplus. Intuitively, they require the c.d.f.s ( $F$ and $G$ ) to be light-tailed (i.e., to have relatively small variance). If the density function $F^{\prime}(\phi)\left(G^{\prime}(\gamma)\right)$ is log-concave, or if it is strictly increasing and the survival function $1-F(\phi)(1-G(\gamma))$ is log-concave, then the hazard rate of $F(G)$ is strictly increasing.

13 In principle, the model could also be developed with the two types of uncertainty together, but the interplay of constraints then makes the analysis intractable. The results for stochastic supply and demand separately are qualitatively similar, although, particularly for expected earnings maximization, there are significant differences of detail.
} 
$\bar{W}-S-\phi-s\left(I^{S}(\bar{W}, \phi)-I^{d}(\bar{W}, \gamma)\right)$ per unit of $I^{d}(\bar{W}, \gamma)$, while at $I^{S}(\bar{W}, \phi)$ it is zero. Taking the mean of these two values, and multiplying by $l^{d}(\bar{W}, \gamma)$, gives total worker surplus,

$$
I^{d}(\bar{W}, \gamma)\left\{\bar{W}-S-\phi-s\left[I^{S}(\bar{W}, \phi)-\left(I^{d}(\bar{W}, \gamma)\right)\right]\right\} / 2=s(R+\gamma-\bar{W})^{2} / 2 r^{2} \equiv \Omega_{1-\alpha}\left(I^{d}(\bar{W}, \gamma), \phi\right) .
$$

Rationing is efficient if $\alpha=1$ and extremely inefficient if $\alpha=0$, whereas if $\alpha=1 / 2$ the allocation of employment is random among those willing to work. ${ }^{14}$ For any $\alpha \in[0,1]$, aggregate worker surplus is therefore

$$
\alpha \Omega_{\alpha}\left(I^{d}(\bar{w}, \gamma), \phi\right)+(1-\alpha) \Omega_{1-\alpha}\left(I^{d}(\bar{w}, \gamma), \phi\right)=(R+\gamma-\bar{w})(2 r \alpha(\bar{w}-S-\phi)-s(2 \alpha-1)(R+\gamma-\bar{w})) / 2 r^{2} \equiv \Omega_{l}(\phi, \gamma) .
$$

We will determine a critical value of $\alpha$ above which results for efficient rationing carry over unchanged.

\section{3 | STOCHASTIC SUPPLY}

We now assume that $\phi$ is a random variable that captures supply uncertainty, while demand is deterministic $(\gamma=0)$. The labor supply and demand schedules become $I^{s}(w, \phi)=(w-S-\phi) / s$ and $I^{d}(w)=(R-w) / r$. From (2), for a given realization of $\phi$, the free market wage and employment are

$$
W^{*}(\phi)=[(S+\phi) r+R s] /(r+s) \text { and } \quad I^{*}(\phi)=(R-S-\phi) /(r+s)
$$

For a given minimum wage $\bar{w}$, the equation for $w^{*}(\phi)$ defines the specific value $\phi=\phi^{*}(\bar{w})$ at which the market clears:

$$
\phi^{*}(\bar{w})=(r+s)\left(\bar{w}-w_{e}^{*}\right) / r
$$

where $w_{e}^{*}$ is given by (3).

From the definitions of $w^{*}(\phi)$ and $\phi^{*}(w)$, it follows that $\operatorname{prob}\left(w^{*}(\phi) \leq \bar{w}\right)=\operatorname{prob}\left(\phi \leq \phi^{*}(\bar{w})\right)=F\left(\phi^{*}(\bar{w})\right)$.

If the minimum wage $\bar{W}$ is set in the high range, where $\bar{w} \in\left(W^{*}\left(\phi_{\max }\right), R\right]$ (so that $\left.\phi^{*}(\bar{W})>\phi_{\max }\right)$ it will bind for all values of $\phi$; that is, $w=\bar{w}$, irrespective of the realization $\phi$. If it is set in the low range, where $\bar{w}<w^{*}\left(\phi_{\min }\right)\left(\right.$ i.e., $\phi^{*}(\bar{w})<$ $\left.\phi_{\min }\right)$ it does not bind, whatever the value of $\phi$, and so there is market clearance at $w=w^{*}(\phi)$. However, in the middle range where $\bar{w} \in\left[w^{*}\left(\phi_{\min }\right), w^{*}\left(\phi_{\max }\right)\right]$ (so that $\phi^{*}(\bar{w}) \in\left[\phi_{\min }, \phi_{\max }\right]$ ), the effect of the minimum wage depends on the value of $\phi$. If labor supply is relatively small at each wage $w$ (when $\left.\phi \in\left[\phi^{*}(\bar{W}), \phi_{\max }\right]\right)$ the minimum wage does not bind $\left(w=w^{*}(\phi)\right)$, whereas for a relatively large labor supply (when $\left.\phi \in\left[\phi_{\min }, \phi^{*}(\bar{w})\right]\right)$ the minimum wage binds and there is rationing $(w=\bar{w})$. For both expected worker surplus and expected earnings maximization, we consider the locally optimal minimum wage in each of these three ranges separately, and then combine the analyses to examine the global optimum.

\subsection{Expected earnings for stochastic supply}

If the government's aim is to maximize expected earnings $E(w l) \equiv E(\Upsilon)$, inefficiency of employment rationing has no effect on the choice of the minimum wage. Moreover, if there is no uncertainty, the minimum wage should then be set such that the elasticity of labor demand is (minus) unity if and only if this minimum wage binds. Thus, with no uncertainty $R / 2$ is the optimal minimum wage if $R / 2>w^{*}(0)$, that is, if $R(r-s)-2 S r>0$, which requires that the demand slope $r$ be sufficiently larger than the supply slope $s$. Otherwise, no minimum wage should be set. With supply uncertainty, however, we must consider the three potential ranges for the minimum wage specified above.

First, if the minimum wage is set in the high range, $\bar{w}>w^{*}\left(\phi_{\max }\right)$, it binds for any $\phi \in\left[\phi_{\min }, \phi_{\max }\right]$ and employment is given by labor demand. If $R / 2>w^{*}\left(\phi_{\max }\right)$ then $\bar{w}=R / 2$ is the globally optimal minimum wage. But if $R / 2 \leq w^{*}\left(\phi_{\max }\right)$

\footnotetext{
14 It is easily shown that a convex combination of the values of worker surplus for $\alpha=1$ and $\alpha=0$ equals the value obtained by setting $\alpha$ appropriately. In particular, with equal weights for $\alpha=1$ and $\alpha=0$, worker surplus is the same as when $\alpha=1 / 2$.
} 


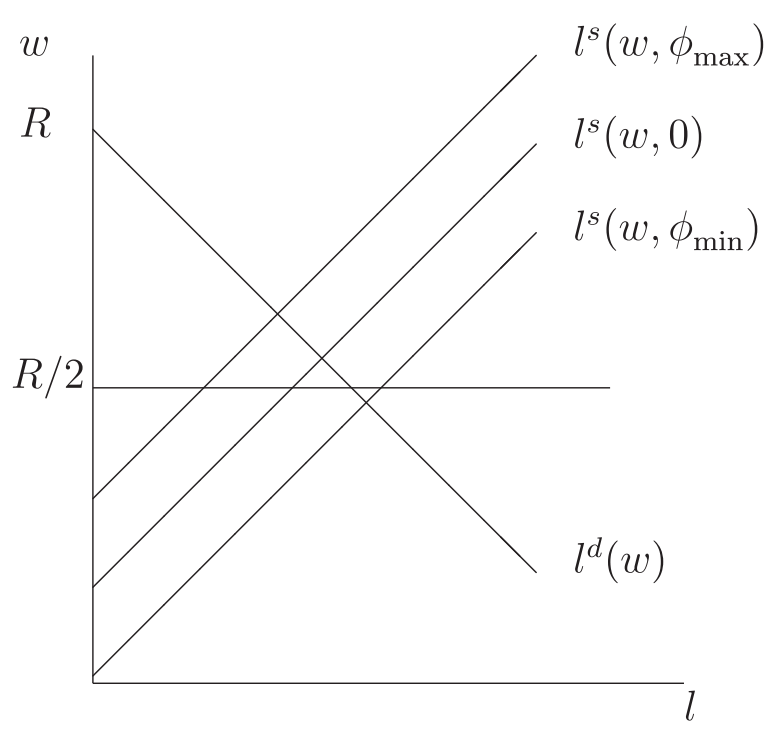

FIGURE 1 Expected earnings with stochastic supply

then, for any realization $\phi$, earnings would be greater at $\bar{w}=w^{*}\left(\phi_{\max }\right)$ than at a higher minimum wage, and so the expected earnings-maximizing minimum wage is not in the high range.

Second, if the minimum wage is set in the low range, $\bar{w}<w^{*}\left(\phi_{\min }\right)$, it does not bind for any realization $\phi$, and so the free-market wage $w^{*}(\phi)$ will obtain. Any minimum wage in this range yields the same outcome as setting $\bar{w}=w^{*}\left(\phi_{\min }\right)$.

Third, consider the middle range, $\bar{w} \in\left[w^{*}\left(\phi_{\min }\right), w^{*}\left(\phi_{\max }\right)\right]$, so that the corresponding $\phi^{*}(\bar{w}) \in\left[\phi_{\min }, \phi_{\max }\right]$. In this range $\bar{w}$ may or not bind, depending on the realization $\phi$. If $\phi \geq \phi^{*}(\bar{W})$, so that $\bar{w} \leq w^{*}(\phi)$, that is, $\bar{w}$ does not bind, earnings are $\Upsilon\left(I^{*}(\phi)\right)$, as evaluated above for $\bar{w}<w^{*}\left(\phi_{\min }\right)$. If $\phi<\phi^{*}(\bar{w})$, so that $\bar{w}>w^{*}(\phi)$, which is binding, there is excess supply and earnings are $\Upsilon\left(I^{d}(\bar{W})\right)$. Combining these two possibilities, we obtain expected earnings for $\bar{w}$ in the middle range,

$$
E(\Upsilon)=\int_{\phi^{*}(\bar{w})}^{\phi_{\max }} \Upsilon\left(I^{*}(\phi)\right) f(\phi) d \phi+\int_{\phi_{\min }}^{\phi^{*}(\bar{w})} \Upsilon\left(I^{d}(\bar{w})\right) f(\phi) d \phi \equiv \Upsilon_{s} .
$$

Comparison of the optimal solution in each of the three ranges gives the following result.

Proposition 1. With labor supply uncertainty, if the wage at which the demand for labor is unit-elastic is at least as large as the market-clearing wage for the lowest demand realization (i.e., if $R / 2 \geq w^{*}\left(\phi_{\min }\right)$ ) expected earnings $E(\Upsilon)$ are maximized by setting the minimum wage at this unit-elastic level: $\bar{w}=R / 2$. Otherwise, no minimum wage should be set.

This is a simple generalization of the solution when there is no uncertainty, with the constraint $R / 2 \geq w^{*}(0)$ replaced by $R / 2 \geq w^{*}\left(\phi_{\min }\right)$; that is, substituting for $w^{*}(\cdot)$ from (2), the constraint $R(r-s)-2 S r>0$ is replaced by $R(r-s)-2\left(S+\phi_{\min }\right) r>0$. Thus, with supply uncertainty the optimal minimum wage, if it exists, is the same as without uncertainty. However, since $\phi_{\min }<0$, the condition under which this minimum wage should be set is milder than when there is no uncertainty. Specifically, suppose that $R(r-s)-2 S r<0$, so that if there were no uncertainty there should be no minimum wage. When instead there is uncertainty, if also $\phi_{\min }$ is more negative $\operatorname{than}[R(r-s)-2 S r] / 2 r$, then the minimum wage should be set. Thus, the existence of uncertainty widens the range of parameter values for which a meaningful (i.e., potentially binding) minimum wage should be set.

The intuition underlying the impact of uncertainty is illustrated in Figure 1. If labor supply is certain, as given by $I^{s}(w, 0)$, then, because the intersection with labor demand $I^{d}(w)$ occurs above $R / 2$, a minimum wage should not be set. Now suppose instead that labor supply is uncertain and that $\phi_{\min }$ is sufficiently negative that the lowest possible labor supply curve, $I^{s}\left(w, \phi_{\min }\right)$, intersects $I^{d}(w)$ below $R / 2$. Assume, as specified in Proposition 1 , that the minimum wage is 
set at $R / 2$. Then, for all ex post realizations of uncertainty such that the supply curve cuts $I^{d}(w)$ above $R / 2$, the minimum wage does not bind, and so has no effect. But for any realization such that supply cuts $I^{d}(w)$ below $R / 2$, the minimum wage $\bar{w}=R / 2$ binds and, by the standard unit-elasticity condition, maximizes earnings. Therefore, considering all possible realizations of $\phi$ together, the imposition of the minimum wage raises expected earnings, and this is because there is sufficient uncertainty.

\subsection{Expected worker surplus for stochastic labor supply}

When expected worker surplus is maximized the solution depends on how efficient rationing is. Again we examine three potential ranges for the minimum wage $\bar{w}$.

First, in the high range, $\bar{w} \in\left(W^{*}\left(\phi_{\max }\right), R\right]$, regardless of the realization $\phi$, demand is a binding constraint. Therefore $I=I^{d}(\bar{W}, \phi)=(R-\bar{W}) / r$ and employment is rationed. Total worker surplus is $\Omega_{l}(\phi)$, as given by (4) for $\gamma=0$. Taking the expectation over all $\phi$ and differentiating with respect to $\bar{W}$, the minimum wage that satisfies the first order condition (f.o.c.) for maximizing expected worker surplus in this range is

$$
\hat{w}(\alpha)=\frac{\alpha r(R+S)+(2 \alpha-1) s R}{2 \alpha(r+s)-s},
$$

which is increasing in $\alpha$, the efficiency of rationing.

However, some restrictions on parameter values are required for $E\left(\Omega_{l}(\phi)\right)$ to be concave at $\bar{w}=\hat{w}(\alpha)$ and for $\hat{w}(\alpha)$ to belong to the interval $\left(w^{*}\left(\phi_{\max }\right), R\right]$. Let $\phi_{0}$ denote the value of $\phi$ at which $w^{*}(\phi)=\hat{w}(\alpha)$, that is, from (5) and (8),

$$
\phi_{0}=\frac{(R-S)[\alpha(r+s)-s]}{2 \alpha(r+s)-s}
$$

This defines the critical level of uncertainty for which (8) is a local optimum. It is also necessary that rationing is not "too inefficient." We show in the proof to the following lemma that the critical condition is that $\alpha>s /(r+s)$.

Lemma 1. With labor supply uncertainty, if $\phi_{\max }<\phi_{0}$ and $\alpha>s /(r+s)$, the minimum wage that maximizes expected worker surplus for $\bar{w} \in\left(w^{*}\left(\phi_{\max }\right), R\right]$ is $\hat{w}(\alpha)$, as given by (8). If $\phi_{\max } \geq \phi_{0}$ the minimum wage that maximizes expected worker surplus cannot be strictly higher than $w^{*}\left(\phi_{\max }\right)$.

Thus, when supply uncertainty is small enough, in the sense that $\phi_{\max }$ is sufficiently small, and if rationing is efficient enough, there is a local maximum $\bar{w}=\hat{w}(\alpha)>w^{*}\left(\phi_{\max }\right)$. For the given mean value $(\phi=0)$ variation of the lower bound may be accompanied by one or both of a redistribution of the mass and a variation of the upper bound. The cutoff level of uncertainty $\phi_{0}$ is decreasing in $\alpha$, so that the condition $\phi_{\max }<\phi_{0}$ is harder to satisfy if rationing is more efficient, ceteris paribus.

If instead a minimum wage is set in the low range $\bar{w}<w^{*}\left(\phi_{\min }\right)$, then, regardless of the realization of $\phi$, it does not bind. The free market wage and employment will be $w^{*}(\phi)$ and $l^{*}(\phi)$, respectively, as given by (5). Worker surplus is

$$
\Omega\left(I^{*}(\phi)\right)=s(R-S-\phi)^{2} / 2(r+s)^{2},
$$

which is the same for all $\bar{w}<w^{*}\left(\phi_{\min }\right)$. Expected worker surplus is therefore the same for any minimum wage in this range (and the same as at $\left.\bar{w}<w^{*}\left(\phi_{\min }\right)\right)$.

Finally, consider the middle range $\bar{w} \in\left[w^{*}\left(\phi_{\min }\right), w^{*}\left(\phi_{\max }\right)\right]$. Parallel to (7) for expected earnings maximization, the maximand is

$$
E(\Omega)=\int_{\phi^{*}(\bar{w})}^{\phi_{\max }} \Omega\left(I^{*}(\phi)\right) f(\phi) d \phi+\int_{\phi_{\min }}^{\phi^{*}(\bar{w})} \Omega_{l}(\phi) f(\phi) d \phi \equiv \Omega_{s} .
$$

Using these expressions together with Lemma 1, we obtain the next result.

Proposition 2. With labor supply uncertainty and $\alpha>s /(r+s)$, the minimum wage that maximizes expected worker surplus is $\hat{w}(\alpha)$, as given by (8), if $\phi_{\max }<\phi_{0}$, but lies in the range $\left(w^{*}\left(\phi_{\min }\right), w^{*}\left(\phi_{\max }\right)\right]$ and is strictly lower than $\hat{w}(\alpha)$ if $\phi_{\max } \geq \phi_{0}$. 
The proposition applies when rationing is sufficiently efficient. Then the location of the expected worker surplusmaximizing minimum wage depends on the extent of uncertainty. Specifically, if uncertainty is small enough (in the sense that $\phi_{\max }<\phi_{0}$, as in Lemma 1) the optimal minimum wage is $\hat{w}(\alpha)$. This minimum wage is in the high range and is sure to bind. If, however, uncertainty is greater, the optimal minimum wage is lower; it lies in the middle range and may or may not bind. In this case, if the minimum wage is ex post binding, so that demand is a constraint, variation of the supply curve has no effect on employment. However, if ex post the minimum wage does not bind, greater supply uncertainty generates a smaller expected worker surplus. ${ }^{15}$ Since supply uncertainty has a negative effect on expected worker surplus if the minimum wage does not bind, and no effect if the minimum wage binds, it favors setting a low minimum wage that is more likely to bind.

Our analysis here rests on the simplifying assumption that $\phi$ is bounded above, and therefore that distinct high and middle ranges for $\bar{w}$ exist. If the assumption were dropped and if nonetheless the distribution had a centrally concentrated mass, the corresponding result would be that $\bar{w}$ would be set at a level at which it would bind with a high probability, rather than certainty. A similar comment applies to the other cases we consider below.

Our qualitative results still obtain if some weight on expected profit is put in the objective function, though if a minimum wage is then optimal the weight on profit causes it to be lower, and so less likely to bind. A reworking of our analysis shows that the critical level of rationing efficiency becomes $\alpha>(s+\beta r) /(r+s)$, where $\beta \in[0,1)$ is the weight put on profit. With little uncertainty, the optimal value of $\bar{w}$ in the high range is then decreasing in the weight $\beta$. A greater weight on profit is associated with a more stringent requirement on the efficiency of rationing for a binding minimum wage to be optimal. These remarks also apply to the stochastic-demand case.

Another variation of the model, that would obtain with either of our objective functions, is to allow for some noncompliance with the minimum wage law. Suppose that, if the minimum wage binds, then, with probability $\delta$ a firm complies with the minimum wage and with probability $1-\delta$ it sets the market wage. We can therefore think of a proportion $\delta$ of firms complying and a proportion $1-\delta$ not complying. For workers in firms that comply, the expected worker surplus or expected earnings gain from a minimum wage would still apply, but for the others there would be no effect. Therefore, as in our model, there would be some conditions under which it would be optimal to set a minimum wage.

We now consider further the effect of rationing inefficiency.

Proposition 3. With labor supply uncertainty, if $\alpha \leq s /(r+s)$, expected worker surplus is maximized by not setting a minimum wage.

For $\alpha \leq s /(r+s)$, the market should be left unregulated, regardless of the degree of supply uncertainty. If, for example, labor supply and demand slopes are equal, a minimum wage should not be set if rationing is random or worse. Moreover, the smaller the demand slope $r$, relative to the supply slope $s$, the greater the rationing efficiency $\alpha$ required for a (possibly binding) minimum wage to be optimal.

The role of any rationing inefficiency can be seen by focusing on the case with no uncertainty, that is, we consider the degenerate case with $\phi_{\min }=\phi_{\max }=0$. In this case the basic result-that to maximize worker surplus when there is no uncertainty a binding minimum wage should be set, provided rationing is efficient enough-would still hold with more general demand and supply functions. As an illustration, suppose rationing is efficient $(\alpha=1)$. Let $I^{d}(w)$ denote labor demand and $w^{s}(I)$ inverse labor supply, and assume that $\partial^{d}(w) / \partial w<0$ and $\partial w^{s}(I) / \partial w>0$. When $w \geq w^{*}(0)$, so that employment is demand-determined (with market clearance a special case), worker surplus is $\Omega=\int_{0}^{l d(w)}\left(w-w^{s}(I)\right) d l$. Using the envelope theorem, $d \Omega\left(w^{*}(0)\right) / d w>0$, that is, a marginal increase in the wage from the free-market equilibrium raises worker surplus. A similar result is shown by Lee and Saez (2012) in their proposition 1.

Figure 2 illustrates how worker surplus $\Omega$ is related to rationing efficiency when there is no uncertainty. With efficient rationing $(\alpha=1), \Omega$ is maximized at a binding minimum wage $(\bar{W}=\hat{w}(1))$ greater than the market-clearing wage $w^{*}$. With less efficient rationing, but still with $\alpha>\alpha_{0}, \Omega$ is everywhere lower and is maximized at a lower minimum wage $(\bar{w}=\hat{w}(\alpha))$. For $\alpha<\alpha_{0}, d \Omega / d \bar{w}<0$, so that no minimum wage is set and $\Omega=\Omega\left(w^{*}(0)\right)$.

${ }^{15}$ Worker surplus for a given $\phi$ equals $(s / 2)\left[(R-S-\phi)^{2} /(r+s)^{2}\right]$, which is decreasing in $\phi$. 
$\Omega$

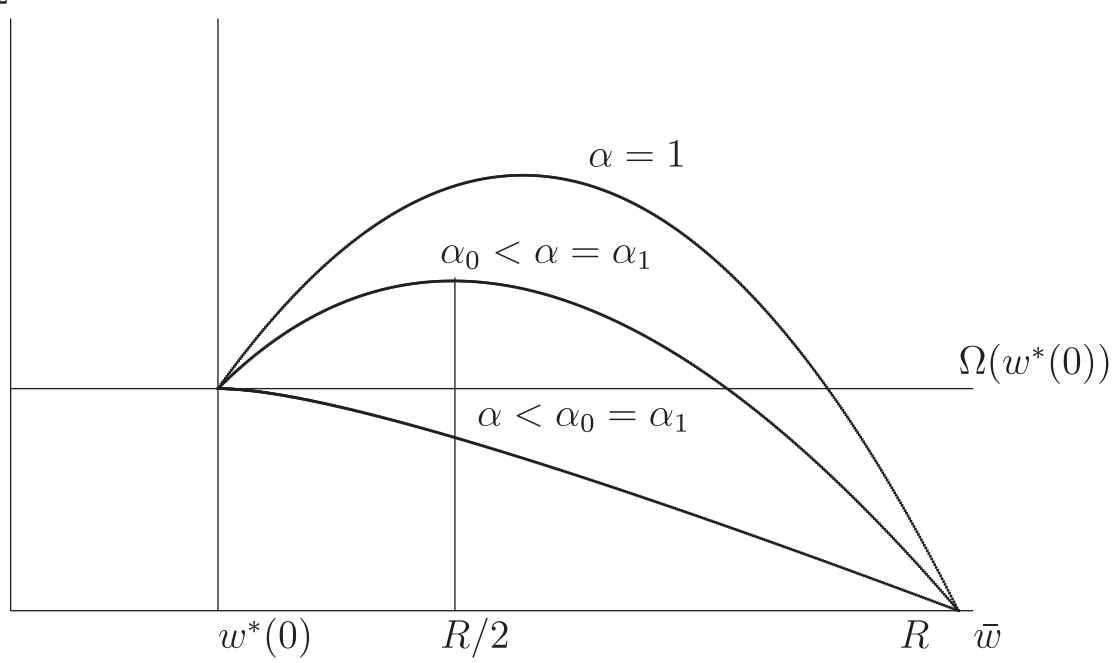

FIGURE 2 Worker surplus for different values of $\alpha\left(R / 2>w^{*}(0)\right)$

It is assumed in Figure 2 that $R / 2>w^{*}(0)$ (i.e., $R(r-s)-2 S r>0$ ), so that a minimum wage $\bar{w}=R / 2$ should be set for earnings maximization. To compare the solutions for the two objective functions, the value of $\alpha$ for the middle $\Omega$-curve is chosen such that worker-surplus maximization occurs at $\bar{w}=R / 2$. Using (8), $\hat{w}(\alpha)-R / 2 \gtreqless 0$ as $\alpha \gtreqless R s /(S r+R s) \equiv \alpha_{1}$. Thus, $\alpha=\alpha_{1}$ for the middle $\Omega$-curve. The worker surplus-maximizing minimum wage exceeds that for earnings maximization if $\alpha \in\left(\alpha_{1}, 1\right.$ ]; but the ranking is reversed if $\alpha \in\left(\alpha_{0}, \alpha_{1}\right]$. However, if $R(r-s)-2 S r \leq 0$, an earnings-maximizing government will not set a minimum wage, whereas a worker surplus-maximizing government will set a minimum wage if and only if $\alpha>\alpha_{0}$.

Intuitively, if $\alpha=1$ the earnings-maximizing minimum wage balances the marginal gain of earnings per unit of labor from the last increment to the wage against the marginal loss of earnings from lower employment. Starting at this level of the minimum wage, if instead the objective is worker surplus maximization, then the marginal gain to worker surplus from the last increment to the wage is the same. But, because earnings below the reservation wage are excluded from the objective function, the marginal loss of worker surplus from the lower employment is smaller than the marginal loss of earnings. The minimum wage should therefore be raised further in the worker surplus-maximizing case.

However, compared to $\alpha=1$, if $\alpha<1$ the reservation wages of those employed are greater, and so the net gain in worker surplus from imposing the minimum wage is smaller. Therefore the minimum wage is set lower, and for sufficiently inefficient rationing $\left(\alpha<\alpha_{1}\right)$ it is set below $R / 2$.

\section{4 | STOCHASTIC LABOR DEMAND}

We now focus on the case of stochastic demand, with deterministic supply. There is some asymmetry with the converse case of Section 3 because each of the objective functions relates only to demand, and not to supply, for any given quantity. Nonetheless, our analysis in this section proceeds similarly to that for stochastic supply, and so some details are omitted. We show that with expected earnings maximization there is a qualitative difference between the results for the two types of uncertainty, whereas for expected worker surplus maximization the results are largely similar to those for stochastic supply.

We assume that $\gamma$ is a random variable that captures demand uncertainty, while $\phi$ is deterministic and equal to zero. For simplicity, our analysis focuses on a minimum wage that satisfies $\bar{w}>R+\gamma_{\min }$; that is, the government only considers a minimum wage that would result in positive employment and (therefore) positive worker surplus and earnings, regardless of the realization of the uncertainty. 
Labor supply and demand are now $I^{S}(w)=(w-S) / s$ and $I^{d}(w)=(R+\gamma-w) / r$, respectively. The free market wage and employment are

$$
W^{*}(\gamma)=[S r+(R+\gamma) s] /(r+s) \text { and } \quad I^{*}(\gamma)=(R+\gamma-S) /(r+s) \text {, }
$$

and, for a given minimum wage $\bar{w},(11)$ defines the specific value $\gamma=\gamma^{*}(\bar{w})$ at which the market clears,

$$
\gamma^{*}(\bar{w})=(r+s)\left(\bar{w}-w_{e}^{*}\right) / s
$$

We again distinguish three ranges of $\bar{w}$. In the low range $\bar{w}<w^{*}\left(\gamma_{\min }\right)$ (so $\left.\gamma^{*}(\bar{w})<\gamma_{\min }\right), \bar{w}$ is nonbinding for all $\gamma \in$ $\left[\gamma_{\min }, \gamma_{\max }\right]$, and the market clears. In the high range $\bar{w}>w^{*}\left(\gamma_{\max }\right)\left(\right.$ so $\left.\gamma^{*}(\bar{w})>\gamma_{\max }\right)$, and there is labor excess supply for all values of $\gamma$. Employment is determined by labor demand and is rationed. In the middle range $\bar{w} \in\left[w^{*}\left(\gamma_{\min }\right), w^{*}\left(\gamma_{\max }\right)\right]$ (so $\gamma^{*}(\bar{w}) \in\left[\gamma_{\min }, \gamma_{\max }\right]$ ), and the effect of a minimum wage depends on the value of $\gamma$. For low demand (when $\gamma \in$ $\left.\left[\gamma_{\min }, \gamma^{*}(\bar{W})\right]\right)$ there is excess supply and rationing, whereas for high demand (when $\left.\gamma \in\left[\gamma^{*}(\bar{W}), \gamma_{\max }\right]\right) \bar{w}$ does not bind.

From the definitions of $w^{*}(\phi)$ and $\phi^{*}(w)$, it follows that $\operatorname{prob}\left(w^{*}(\gamma) \leq \bar{w}\right)=\operatorname{prob}\left(\gamma \leq \gamma^{*}(\bar{w})\right)=G\left(\gamma^{*}(\bar{w})\right)$.

\subsection{Expected earnings for stochastic labor demand}

In our analysis of expected earnings maximization for uncertain supply there is a single level of $\bar{w}$ at which labor demand is unit-elastic. However, with demand uncertainty, for any realization $\gamma$, unit elasticity obtains at $\bar{w}=(R+\gamma) / 2$, that is, at a different level of $\bar{w}$ for each $\gamma$. This leads to a qualitative difference between the results for demand uncertainty and those for supply uncertainty. We again consider three ranges for the minimum wage $\bar{w}$.

If $\bar{w}$ is set in the high range, $\bar{w}>w^{*}\left(\gamma_{\max }\right)$, then for any realization $\gamma \in\left[\gamma_{\min }, \gamma_{\max }\right]$ employment is given by labor demand. Expected earnings are then

$$
E(\Upsilon)=\int_{\gamma_{\min }}^{\gamma_{\min }} \Upsilon\left(I^{d}(\bar{w})\right) g(\gamma) d \gamma=\frac{\bar{W}}{r} \int_{\gamma_{\min }}^{\gamma_{\min }}(R-\bar{W}+\gamma) g(\gamma) d \gamma=\frac{\bar{W}}{r}(R-\bar{w}) .
$$

Hence, if $R / 2>w^{*}\left(\gamma_{\max }\right)$, expected earnings are maximized at $\bar{w}=R / 2=E((R+\gamma) / 2)$. However, if $R / 2 \leq w^{*}\left(\gamma_{\max }\right)$ then $d E(\Upsilon) / d \bar{w}<0$ in this range.

If, instead, the minimum wage is set in the low range, $\bar{w}<w^{*}\left(\gamma_{\min }\right)$, then employment is given by labor supply at $w=\bar{w}$, and so earnings can be increased by raising $\bar{w}$ out of this range at least as far as $W^{*}\left(\gamma_{\min }\right)$.

Thus, provided $R / 2 \leq w^{*}\left(\gamma_{\max }\right), E(\Upsilon)$ is maximized in the middle range $\bar{w} \in\left[w^{*}\left(\gamma_{\min }\right), w^{*}\left(\gamma_{\max }\right)\right]$. In this range, parallel to (7), the maximand is

$$
E(\Upsilon)=\int_{\gamma^{*}(\bar{w})}^{\gamma_{\max }} \Upsilon\left(I^{*}(\gamma)\right) g(\gamma) d \gamma+\int_{\gamma_{\min }}^{\gamma^{*}(\bar{w})} \Upsilon\left(I^{d}(\bar{w})\right) g(\gamma) d \gamma \equiv \Upsilon_{d}
$$

Using (13) we then obtain the following result.

Proposition 4. Consider the minimum wage $\bar{w}$ that maximizes expected earnings when there is labor demand uncertainty. If $R / 2$, the wage at which expected labor demand is unit-elastic, is at least as large as $w^{*}\left(\gamma_{\max }\right)$ the optimal minimum wage is $R / 2$; if $R / 2 \in\left(w^{*}\left(\gamma_{\min }\right), w^{*}\left(\gamma_{\max }\right)\right)$ the optimal minimum wage $\bar{w} \in\left(w^{*}\left(\gamma_{\min }\right), w^{*}\left(\gamma_{\max }\right)\right)$ and is less than $R / 2 ;$ but if $R / 2 \leq w^{*}\left(\gamma_{\min }\right)$ no minimum wage should be set.

Here, the condition for it to be optimal to set a minimum wage is that $R / 2>w^{*}\left(\gamma_{\min }\right)$. Using (11), this can be written as $R(r-s)-2\left(S r+s \gamma_{\min }\right)>0$. By a parallel argument to that made in relation to Proposition 1 for labor supply uncertainty, it follows that, with expected earnings maximization, the existence of labor demand uncertainty extends the set of parameter values for which it is optimal to set a minimum wage. However, in Proposition 4 the minimum wage is potentially below $R / 2$, and so it is qualitatively different to the solution for supply uncertainty.

The intuitive rationale for this result can be seen from Figure 3. Suppose first that labor demand is known ( $\gamma=0)$, with intercept $R$. Given that labor supply $I^{s}(w)$ cuts labor demand $I^{d}(w, 0)$ above $R / 2$, a minimum wage should not be set. Now suppose instead that labor demand is stochastic, and assume that $\gamma_{\min }$ is sufficiently negative for $I^{d}\left(W, \gamma_{\min }\right)$ 


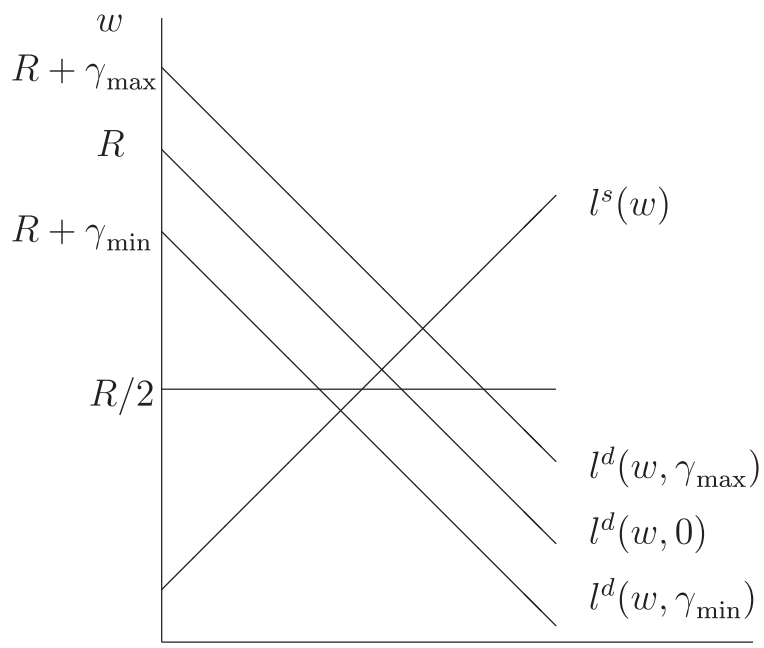

FIGURE 3 Expected earnings with stochastic labor demand

to intersect with $I^{S}(w)$ below $R / 2$, as shown. If the minimum wage $\bar{w}=E((R+\gamma) / 2)=R / 2$ were set, then for all low demand realizations $(\gamma<0),(R+\gamma) / 2$ would be lower than $R / 2$, while for all high demand realizations $(\gamma>0)(R+\gamma) / 2$ would be higher than $R / 2$. But, for any given realization $\gamma$, earnings are maximized at $w=(R+\gamma) / 2$. Therefore, because for any realization $\gamma<0$ a marginal reduction in $\bar{w}$ would be in the direction of $(R+\gamma) / 2$, this would raise realized earnings. But for any realization $\gamma>0$, the minimum wage would not bind and so the reduction in the minimum wage would have no effect on earnings. Thus, the expectation of earnings would be increased by the reduction in $\bar{w}$.

This discussion highlights two properties of expected-earnings maximization for stochastic labor demand that are consistent with our theme that uncertainty leads to a (weakly) lower optimal minimum wage. First, for values of the parameters $(R, S, r, s)$ for which, under certainty, a minimum wage should not be set, with uncertainty-as represented by a sufficiently large $\gamma_{\min }-$ a minimum wage becomes optimal. Second, the optimal minimum wage in this case is less than $\bar{w}=E((R+\gamma) / 2)=R / 2$.

\section{2 | Expected worker surplus for stochastic labor demand}

When the government maximizes expected worker surplus with stochastic demand, the qualitative results are similar to the stochastic supply case. The main difference is that an extra condition must be imposed for concavity of the objective function when uncertainty is sufficiently large and rationing relatively efficient.

For $\bar{w}$ in the high range $\bar{w}>w^{*}\left(\gamma_{\max }\right)$, demand $l^{d}(\bar{w})=(R+\gamma-\bar{w}) / r$ is a binding constraint, regardless of the realization $\gamma$. Expected worker surplus is $\Omega_{l}(\gamma)$, as given by setting $\phi=0$ in (4). Let

$$
\gamma_{0}=\frac{(R-S) r[\alpha(r+s)-s]}{s[2 \alpha(r+s)-s]} \quad \text { and } \quad \gamma_{1}=-\frac{\alpha r(R-S)}{2 \alpha(r+s)-s} .
$$

Parallel to the definition of $\phi_{0}$ for supply uncertainty, $\gamma_{0}$ is the value of $\gamma$ at which $w^{*}(\gamma)=\hat{w}(\alpha)$, whereas $\gamma_{1}$ is the value of $\gamma$ at which $\gamma+S=\hat{w}(\alpha)$. Then, corresponding to Lemma 1 for supply uncertainty, we specify conditions under which (8) is a well-defined local optimum for $\bar{w}>w^{*}\left(\gamma_{\max }\right)$. Lemma 2 parallels Lemma 1 except that it has the additional requirement that $\gamma_{\min }>\gamma_{1}$. As we restrict attention to $\bar{w}<R+\gamma_{\min }$, this requirement is needed so that $\hat{w}(\alpha)<R+\gamma_{\min }$.

Lemma 2. With labor demand uncertainty, if $\gamma_{\max }<\gamma_{0}, \gamma_{\min }>\gamma_{1}$ and $\alpha>s /(r+s)$, the minimum wage $\bar{w}$ that maximizes expected worker surplus for $\bar{w} \in\left(w^{*}\left(\gamma_{\max }\right), R\right]$ is $\hat{w}(\alpha)$, as given by (8). If $\gamma_{\max } \geq \gamma_{0}$ or $\alpha \leq s /(s+r)$, the minimum wage that maximizes expected worker surplus cannot be strictly higher than $w^{*}\left(\gamma_{\max }\right)$. 
Consider now a minimum wage in the low range $\bar{w}<w^{*}\left(\gamma_{\min }\right)$. In this case, regardless of the realization of $\gamma, \bar{w}$ does not bind, and so the free market wage $w^{*}(\gamma)$ and employment $l^{*}(\gamma)$ obtain, as given by $(11)$. Worker surplus is

$$
\Omega\left(I^{*}(\gamma)\right)=s(R+\gamma-S)^{2} / 2(r+s)^{2}
$$

Expected worker surplus is therefore

$$
s\left[(R-S)^{2}+E\left(\gamma^{2}\right)\right] / 2(r+s)^{2} \equiv \Omega_{U}^{d}
$$

which is independent of $\bar{W}$.

Finally, suppose $\bar{w} \in\left[w^{*}\left(\gamma_{\min }\right), w^{*}\left(\gamma_{\max }\right)\right]$ (so that $\left.\gamma^{*}(\bar{w}) \in\left[\gamma_{\min }, \gamma_{\max }\right]\right)$. In this range, any $\bar{w} \leq w^{*}(\gamma)$ (i.e., $\gamma \geq \gamma^{*}(\bar{w})$ ), is nonbinding and worker surplus is given by $\Omega\left(l^{*}(\gamma)\right.$ ) in (14). For $\bar{w} \geq w^{*}(\gamma)$ (i.e., $\gamma<\gamma^{*}(\bar{w})$ ) there is excess supply and worker surplus is $\Omega_{l}(\gamma)$, as given by (4) with $\phi=0$. Expected worker surplus is therefore

$$
E(\Omega)=\int_{\gamma^{*}(\bar{w})}^{\gamma_{\max }} \Omega\left(I^{*}(\gamma)\right) g(\gamma) d \gamma+\int_{\gamma_{\min }}^{\gamma^{*}(\bar{w})} \Omega_{l}(\gamma) g(\gamma) d \gamma \equiv \Omega_{d} .
$$

We can now derive the following result.

Proposition 5. With labor demand uncertainty and $\alpha>s /(r+s)$, the minimum wage that maximizes expected worker surplus is $\hat{w}(\alpha)$, as given by (8), if $\gamma_{\max }<\gamma_{0}$ and $\Omega_{d}$ is single-peaked, but it lies in the range $\left(w^{*}\left(\gamma_{\min }\right), w^{*}\left(\gamma_{\max }\right)\right]$ and is strictly lower than $\hat{w}(\alpha)$ if $\gamma_{\max } \geq \gamma_{0}$.

Assuming that rationing is relatively efficient $(\alpha>s /(r+s))$, if uncertainty is small enough $\left(\gamma_{\max }<\gamma_{0}\right)$, a sufficient condition for the optimal minimum wage to be $\bar{w}=\hat{w}(\alpha)$ in the high range (and certainly binding) is that $\Omega_{d}$ is singlepeaked. ${ }^{16}$ If uncertainty is larger $\left(\gamma_{\max } \geq \gamma_{0}\right)$, the optimal minimum wage is in the middle range $\left(w^{*}\left(\gamma_{\min }\right), w^{*}\left(\gamma_{\max }\right)\right]$, so that it may or may not bind and is strictly lower than $\hat{w}(\alpha)$. We show in the proof of Proposition 5 that $\Omega_{d}$ must have an inflexion point in this range. If the inflexion point is unique, $\Omega_{d}$ is single-peaked and so the optimal minimum wage is also unique. A sufficient condition for this is for $d^{2} \Omega_{d} / d \bar{w}^{2}$ to be strictly monotonic on $\left(w^{*}\left(\gamma_{\min }\right), w^{*}\left(\gamma_{\max }\right)\right]$. This is true, for instance, if $\gamma$ is uniformly distributed.

Finally, for low rationing efficiency, $\alpha \leq s /(r+s)$, a result parallel to that for supply uncertainty obtains.

Proposition 6. With labor demand uncertainty, if $\alpha \leq s /(r+s)$, expected worker surplus is maximized by not setting a minimum wage.

As in the case of stochastic labor supply, this result does not depend on the amount of uncertainty.

\section{5 | CONCLUSION}

Recognition of regulatory uncertainty might be expected to diminish the case for policy intervention such as a minimum wage. However, if the objective is to maximize expected earnings, such uncertainty expands the range of parameter values for which a minimum wage should be set, though it has a weakly negative effect on the optimal level. This minimum wage may or may not bind ex post. Additionally, the qualitative impact of the uncertainty depends on whether the uncertainty relates to supply or demand. In the former case the optimal minimum wage is obtained by a simple modification of the unit-demand-elasticity rule that applies under certainty, whereas in the latter case the solution is less clear-cut.

If the objective is to maximize expected worker surplus, a minimum wage should always be set, provided the efficiency of employment rationing is above a critical level. Uncertainty has no effect on whether a minimum wage should be used, but, as with expected earnings maximization, if uncertainty is sufficiently great, the minimum wage should be

${ }^{16}$ Without this condition we cannot rule out the possibility that $\Omega_{d}$ will be greater in the middle than in the high range. 
set at a level that may or may not bind. This minimum wage is lower than the optimal minimum wage when there is no uncertainty. Thus, our analysis shows that regulatory uncertainty has a weakly negative effect on the optimal minimum wage, but does not reduce the scope for intervention.

Our qualitative results would still apply if profit were added to the worker-surplus objective function, though with a lower weight. Also, future research might develop the analysis for more general demand and supply functions and for monopsony. We conjecture that the optimal minimum wage will then be weakly higher than with perfect competition to keep up expected worker surplus or earnings for those realizations at which monopsonistic behavior, but not competition, would be restrictive.

The main message of our paper, that regulatory uncertainty does not undermine the case for introducing a minimum wage but that it may call for a conservative level to be set, bears on recent debates. For the minimum wage law recently rejected by Switzerland, the Kaitz index (the ratio of the minimum wage to median earnings) was $2 / 3$, which, it was said, would have been the highest in the world (Financial Times, May 18, 2014). In contrast, a minimum wage with a Kaitz index of $1 / 2$ was adopted by Germany. Although this puts the German minimum wage well above the OECD average, the rejection of a higher minimum wage in Switzerland and adoption of a somewhat lower one in Germany could be regarded as consistent with our analysis. However, the determination of an appropriately conservative level for the minimum wage remains an empirical question.

\section{APPENDIX}

Proof of Proposition 1. We consider the two parts of (7) in turn. The first term is the value of $E(\Upsilon)$ conditional on $\bar{w} \leq w^{*}(\phi)$ (i.e., $\left.\phi \geq \phi^{*}(\bar{W})\right) . \bar{W}$ does not bind, so from (5), $\Upsilon=l^{*}(\phi) w^{*}(\phi)=[(S+\phi) r+R s](R-S-\phi) /(r+s)^{2}$, and

$$
\int_{\phi^{*}(\bar{w})}^{\phi_{\max }} \Upsilon\left(I^{*}(\phi)\right) f(\phi) d \phi=\frac{(S r+R s)(R-S)\left(1-F\left(\phi^{*}(\bar{w})\right)\right)-(2 S r+R s-R r) \epsilon_{s}^{H}\left(\phi^{*}(\bar{w})\right)-r \sigma_{s}^{H}\left(\phi^{*}(\bar{w})\right)}{(r+s)^{2}},
$$

where $\epsilon_{s}^{H}\left(\phi^{*}(\bar{W})\right)=\int_{\phi^{*}(\bar{W})}^{\phi_{\max }} \phi f(\phi) d \phi$ and $\sigma_{s}^{H}\left(\phi^{*}(\bar{W})\right)=\int_{\phi^{*}(\overline{\mathrm{W}})}^{\phi_{\max }} \phi^{2} f(\phi) d \phi$.

The second term is $E(\Upsilon)$ conditional on $\bar{W}>w^{*}(\phi)$ (i.e., $\phi<\phi^{*}(\bar{W})$ ). There is excess supply, so $\Upsilon=\bar{W} l^{d}(w)=\bar{W}(R-\bar{W}) / r$. The conditional expectation of $\Upsilon$ is then

$$
\int_{\phi_{\min }}^{\phi^{*}(\bar{w})} \Upsilon\left(I^{d}(\bar{w})\right) f(\phi) d \phi=\frac{1}{r} \int_{\phi_{\min }}^{\phi^{*}(\bar{w})} \bar{w}(R-\bar{w}) f(\phi) d \phi=\frac{1}{r} F\left(\phi^{*}(\bar{w})\right) \bar{w}(R-\bar{w}),
$$

Substituting these expressions into (7) and using (6), ${ }^{17}$

$$
\frac{d \Upsilon_{s}}{d \bar{w}}=\frac{1}{r}(R-2 \bar{w}) F\left(\phi^{*}(\bar{w})\right) \quad \text { and } \quad \frac{d^{2} \Upsilon_{s}}{d \bar{w}^{2}}=-\frac{2}{r} F\left(\phi^{*}(\bar{w})\right)+\frac{r+s}{r^{2}}(R-2 \bar{w}) F^{\prime}\left(\phi^{*}(\bar{w})\right)
$$

Now consider how the global optimum changes with $R / 2$. If $R / 2$ is below the high range, $\Upsilon_{S}$ is increased by reducing $\bar{w}$ at least to $w^{*}\left(\phi_{\max }\right)$. If $R / 2$ is above the low range $\Upsilon_{s}$ is weakly increased if $\bar{w}$ is raised at least to $w^{*}\left(\phi_{\min }\right)$. If $R / 2$ belongs to the middle range $\left[W^{*}\left(\phi_{\min }\right), w^{*}\left(\phi_{\max }\right)\right]$ then, using the expression above, $d Y_{s} / d \bar{w}$ is positive at $\bar{w}=w^{*}\left(\phi_{\min }\right)$ and negative at $\bar{w}=w^{*}\left(\phi_{\max }\right)$. Since the f.o.c. $d \Upsilon_{s} / d \bar{w}=0$ is satisfied at $\bar{w}=R / 2$, at which the second order condition (s.o.c.) $d^{2} \Upsilon_{s} / d \bar{w}^{2}<0$ holds, the proposition follows.

Proof of Lemma 1. If $\alpha<2 s /(r+s)$ then $\hat{w}(\alpha)>R$, which is inconsistent with the range $\left(w^{*}\left(\phi_{\max }\right), R\right]\left(\right.$ and gives an $E\left(\Omega_{l}(\phi)\right)$ minimum). If $\alpha>s / 2(r+s)$ and $\phi_{\max } \geq \phi_{0}, d E\left(\Omega_{l}(\phi)\right) / d \bar{w}<0$ for all $\bar{w}>w^{*}\left(\phi_{\max }\right)$; also, $\hat{w}(\alpha) \leq w^{*}\left(\phi_{\max }\right)$, which is inconsistent with the range $\left(w^{*}\left(\phi_{\max }\right), R\right]$. If $\alpha \in(s / 2(r+s), s /(r+s))$, since $R>S$ and $\phi_{\max }>0$, the condition $\phi_{\max }>\phi_{0}$ is trivially satisfied, and so $\hat{w}(\alpha)<w^{*}\left(\phi_{\max }\right)$. However, if $\phi_{\max }<\phi_{0}$ and $\alpha>s /(r+s)$, as $d^{2} E\left(\Omega_{l}(\phi)\right) / d \bar{w}^{2}<0$, (8) is a well-defined local maximum within the range $\left(W^{*}\left(\phi_{\max }\right), R\right]$.

\footnotetext{
17 It is straightforward to show that expected earnings are continuous and differentiable at the boundaries of the middle range with the other ranges, as well as within each range (though for brevity we do not show this). This comment also applies for the other optimizations we undertake.
} 
Proof of Proposition 2. Assume $\alpha>s /(r+s)$. Suppose $\phi_{\max } \geq \phi_{0}$ and consider $\bar{w} \in\left(w^{*}\left(\phi_{\min }\right), w^{*}\left(\phi_{\max }\right)\right]$. Substituting for the two terms in (10) and differentiating w.r.t. $\bar{w}$ we find the local optimum for $\bar{w} \in\left[w^{*}\left(\phi_{\min }\right), w^{*}\left(\phi_{\max }\right)\right]$. Using (4) and (9),

$$
\begin{aligned}
& \int_{\phi^{*}(\bar{w})}^{\phi_{\max }} \Omega\left(I^{*}(\phi)\right) f(\phi) d \phi=\frac{s}{2(r+s)^{2}}\left[\left(1-F\left(\phi^{*}(\bar{w})\right)(R-S)^{2}-2 \epsilon_{s}^{H}\left(\phi^{*}(\bar{w})\right)(R-S)+\sigma_{s}^{H}\left(\phi^{*}(\bar{w})\right)\right] \quad\right. \text { and } \\
& \int_{\phi_{\min }}^{\phi^{*}(\bar{w})} \Omega_{l}(\phi) f(\phi) d \phi=\frac{R-\bar{w}}{2 r^{2}}\left\{F\left(\phi^{*}(\bar{w})\right)[2 \alpha r(\bar{w}-S)+(1-2 \alpha) s(R-\bar{w})]-2 \alpha r \epsilon_{s}^{L}\left(\phi^{*}(\bar{w})\right)\right\}
\end{aligned}
$$

where $\epsilon_{s}^{L}\left(\phi^{*}(\bar{w})\right)=\int_{\phi_{\min }}^{\phi^{*}(\bar{w})} \phi f(\phi) d \phi$. Substituting these expressions into (10) and using (6), we obtain

$$
\begin{aligned}
\frac{d \Omega_{s}}{d \bar{w}} & =\frac{\alpha}{r} \epsilon_{s}^{L}\left(\phi^{*}(\bar{w})\right)+\frac{1}{r^{2}} F\left(\phi^{*}(\bar{w})\right)\{[2 \alpha(r+s)-s](R-\bar{w})-\alpha r(R-S)\} ; \\
\frac{d^{2} \Omega_{s}}{d \bar{w}^{2}} & =-\frac{1}{r^{2}} F\left(\phi^{*}(\bar{w})\right)[2 \alpha(r+s)-s]+\frac{1}{r^{3}}(R-\bar{w})(r+s)[\alpha(r+s)-s] F^{\prime}\left(\phi^{*}(\bar{w})\right) .
\end{aligned}
$$

With $\alpha>s /(r+s)$, because $\epsilon_{s}^{L}\left(\phi_{\min }\right)=F\left(\phi_{\min }\right)=0, w^{*}\left(\phi_{\min }\right)$ satisfies the f.o.c. $d \Omega_{s} / d \bar{w}=0$. However, this is a local minimum, for $\Omega_{s}$ is convex at this point. In addition, we have seen that all $\bar{W}<w^{*}\left(\phi_{\min }\right)$ result in the same levels of expected worker surplus as $\bar{w}=w^{*}\left(\phi_{\min }\right)$ does.

Using (6) and (16), $d \Omega_{s} / w^{*}\left(\phi_{\max }\right)<0$ iff $\phi_{\max } \geq \phi_{0}$. Also, by Lemma 1, if $\alpha>s /(r+s)$ and $\phi_{\max } \geq \phi_{0}$ there is no candidate optimal $\bar{W}>W^{*}\left(\phi_{\max }\right)$, and so the global optimal $\bar{w} \in\left(w^{*}\left(\phi_{\min }\right), w^{*}\left(\phi_{\max }\right)\right]$. Furthermore, we can show that there is a unique optimal $\bar{w}$ in this interval. For $\alpha>s /(r+s)$,

$$
\operatorname{sign} \frac{d^{2} \Omega_{s}}{d \bar{w}^{2}}=\operatorname{sign}\left(\frac{F^{\prime}\left(\phi^{*}(\bar{w})\right)}{F\left(\phi^{*}(\bar{w})\right)}-\frac{(2 \alpha(r+s)-s) r}{(r+s)(\alpha(r+s)-s)} \frac{1}{R-\bar{w}}\right) .
$$

By assumption, $F^{\prime}(\phi) /(1-F(\phi))$ is strictly increasing on $\left(w^{*}\left(\phi_{\min }\right), w^{*}\left(\phi_{\max }\right)\right]$, and so $F^{\prime}(\phi) / F(\phi)$ is strictly decreasing in this range. ${ }^{18}$ As $1 /(R-\bar{w})$ is strictly increasing in $\bar{w}, \Omega_{s}$ has a unique inflexion point at $w_{1}^{s}$. At $w^{*}\left(\phi_{\min }\right), w h e n \alpha>s /(r+s)$, $d^{2} \Omega_{s} / d \bar{w}^{2}>0$, so that the function is convex for all $\bar{w} \in\left(w^{*}\left(\phi_{\min }\right), w_{l}^{s}\right)$. However, if $\bar{w}>w_{I}^{S}, 1 /(R-\bar{w})$ will take a lower value and $F^{\prime}\left(\phi^{*}(\bar{w})\right) / F\left(\phi^{*}(\bar{w})\right)$ a higher one, so that $d^{2} \Omega_{s} / d \bar{w}^{2} \leq 0$ for all $\bar{w} \in\left(w_{l}^{s}, w^{*}\left(\phi_{\max }\right)\right)$. Hence, if $\alpha>s /(r+s)$ and $\phi_{\min } \geq \phi_{0}$, there is a unique optimal $\bar{W}$ on $\left(w^{*}\left(\phi_{\min }\right), w^{*}\left(\phi_{\max }\right)\right]$.

We have seen that if $\phi_{\max }<\phi_{0}$, the optimal $\bar{w}=\hat{w}(\alpha)$ cannot lie in the range $\left(w^{*}\left(\phi_{\min }\right), w^{*}\left(\phi_{\max }\right)\right]$. Together with the findings in Lemma 1, this establishes the solutions for both $\phi_{\max }<\phi_{0}$ and $\phi_{\max } \geq \phi_{0}$. It remains to compare the values of $\bar{w}$ in these two solutions.

When $\phi_{\max } \geq \phi_{0}$, so that the optimal $\bar{w} \in\left(w^{*}\left(\phi_{\min }\right), w^{*}\left(\phi_{\max }\right)\right], \hat{w}(\alpha)$ also belongs in this range. However, evaluating (16) at $\hat{w}(\alpha)$, we obtain

$$
\frac{d \Omega_{s}(\hat{w}(\alpha))}{d \bar{w}}=\frac{\alpha}{r} \epsilon_{s}^{L}\left(\phi^{*}(\hat{w}(\alpha))\right) \leq 0
$$

which holds with equality only for $\phi_{\max }=\phi_{0}$ (or, $\left.w^{*}\left(\phi_{\max }\right)=\hat{p}\right)$. Therefore, if $\phi_{\max } \geq \phi_{0}$ the optimal $\bar{w}$ on $\left(w^{*}\left(\phi_{\min }\right), w^{*}\left(\phi_{\max }\right)\right]$ is strictly lower than $\hat{w}(\alpha)$.

Proof of Proposition 3. Assume $\alpha \leq s /(r+s)$. Then, from (16), $d \Omega_{s}\left(w^{*}\left(\phi_{\min }\right)\right) / d \bar{w}=0$ and $d^{2} \Omega_{s}\left(w^{*}\left(\phi_{\min }\right)\right) / d \bar{w}^{2}<0, s o$ that $w^{*}\left(\phi_{\min }\right)$ is a local maximum on $\bar{w} \in\left[w^{*}\left(\phi_{\min }\right), w^{*}\left(\phi_{\max }\right)\right]$. Also, from $(4), d E\left(\Omega_{l}(\phi)\right) / d \bar{w}<0$ for all $\bar{w}>w^{*}\left(\phi_{\max }\right)$. Finally, any $\bar{w} \leq w^{*}\left(\phi_{\min }\right)$ does not bind, and so gives the same outcome. Therefore $w^{*}\left(\phi_{\min }\right)$ is a well-defined maximum in the range $\left[w^{*}\left(\phi_{\min }\right), w^{*}\left(\phi_{\max }\right)\right]$, and any $\bar{w}<w^{*}\left(\phi_{\min }\right)$ yields the same outcome, whereas $\Omega_{s}$ is lower for $\bar{w}>w^{*}\left(\phi_{\max }\right)$. This proves the result.

Proof of Proposition 4. We first derive the f.o.c. and s.o.c. for the middle range $\bar{w} \in\left[w^{*}\left(\gamma_{\min }\right), w^{*}\left(\gamma_{\max }\right)\right]$.

18 The strictly increasing hazard rate can be written, $F^{\prime \prime}(\phi)(1-F(\phi))+\left(F^{\prime}(\phi)\right)^{2}=x>0$. However, $\operatorname{sign}\left(\frac{d}{d \phi}\left(F^{\prime}(\phi) / F(\phi)\right)\right)=\operatorname{sign}\left(F^{\prime \prime}(\phi) F(\phi)-\left(F^{\prime}(\phi)\right)^{2}\right)=\operatorname{sign}(y)$. But since $x=F^{\prime \prime}(\phi)(1-F(\phi))+\left(F^{\prime}(\phi)\right)^{2}>0, F^{\prime \prime}(\phi) F(\phi)-\left(F^{\prime}(\phi)\right)^{2}=y<F^{\prime \prime}(\phi) F(\phi)+F^{\prime \prime}(\phi)(1-F(\phi))=F^{\prime \prime}(\phi)<0 ;$ i.e., $F^{\prime}(\phi) / F(\phi)$ is strictly decreasing. 
We consider the two parts of (13) in turn. If $\bar{W} \leq W^{*}(\gamma)$ (i.e., $\left.\gamma \geq \gamma^{*}(\bar{W})\right) \bar{W}$ does not bind, so that, from $(11), \Upsilon=I^{*} W^{*}(\gamma)=$ $[S r+(R+\gamma) s](R+\gamma-S) /(r+s)^{2} . E(\Upsilon)$ in this range is therefore

$$
\begin{aligned}
& \int_{\gamma^{*}(\bar{w})}^{\gamma_{\max }} \Upsilon\left(I^{*}(\gamma)\right) g(\gamma) d \gamma=\frac{1}{(r+s)^{2}} \int_{\gamma^{*}(\bar{w})}^{\gamma_{\max }}[S r+(R+\gamma) s](R+\gamma-S) g(\gamma) d \gamma \\
& =\frac{1}{(r+s)^{2}}\left[(S r+R s)(R-S)\left(1-G\left(\gamma^{*}(\bar{w})\right)\right)+(2 R s+S r-s S) \epsilon_{d}^{H}\left(\gamma^{*}(\bar{w})\right)+s \sigma_{d}^{H}\left(\gamma^{*}(\bar{W})\right)\right]
\end{aligned}
$$

where $\epsilon_{d}^{H}\left(\gamma^{*}(\bar{w})\right)=\int_{\gamma^{*}(\bar{w})}^{\gamma_{\max }} \gamma g(\gamma) d \gamma$ and $\sigma_{d}^{H}\left(\gamma^{*}(\bar{w})\right)=\int_{\gamma^{*}(\bar{w})}^{\gamma_{\max }} \gamma^{2} g(\gamma) d \gamma$. However, if $\bar{w}>w^{*}(\gamma)$ (i.e., $\left.\gamma<\gamma^{*}(\bar{w})\right)$ there is excess supply, so that $\Upsilon=\bar{w} l^{d}(W)=\bar{W}(R+\gamma-\bar{w}) / r$. $E(\Upsilon)$ is

$$
\int_{\gamma_{\min }}^{\gamma^{*}(\bar{w})} \Upsilon\left(I^{d}(\bar{w})\right) g(\gamma) d \gamma=\frac{\bar{w}}{r} \int_{\gamma_{\min }}^{\gamma^{*}(\bar{w})}(R-\bar{w}+\gamma) g(\gamma) d \gamma=\frac{\bar{w}}{r}\left[(R-\bar{w}) G\left(\gamma^{*}(\bar{w})\right)+\epsilon_{d}^{L}(\bar{w})\right],
$$

where $\epsilon_{d}^{L}\left(\gamma^{*}(\bar{w})\right)=\int_{\gamma_{\min }}^{\gamma^{*}(\bar{w})} \gamma g(\gamma) d \gamma$.

Substituting these expressions into (13), and using (12), we obtain

$$
\frac{d \Upsilon_{d}}{d \bar{w}}=\frac{1}{r}(R-2 \bar{w}) G\left(\gamma^{*}(\bar{W})\right)+\frac{1}{r} \epsilon_{d}^{L}(\bar{w}) ; \quad \frac{d^{2} \Upsilon_{d}}{d \bar{w}^{2}}=-\frac{2}{r} G\left(\gamma^{*}(\bar{w})\right)-(s+r) \frac{\bar{w}(s-r)+r S}{r s^{2}} G^{\prime}\left(\gamma^{*}(\bar{w})\right) .
$$

The second derivative above can be written

$$
\frac{d^{2} \Upsilon_{d}}{d \bar{w}^{2}}=-\frac{2 G^{\prime}\left(\gamma^{*}(\bar{W})\right)}{r}\left[\frac{G\left(\gamma^{*}(\bar{W})\right)}{G^{\prime}\left(\gamma^{*}(\bar{W})\right)}+(s+r) \frac{\bar{W}(s-r)+r S}{2 s^{2}}\right]
$$

If $s \geq r$ this is negative. But suppose $s<r$. Since $d \Upsilon_{d} / d \bar{w}>0$ at $\bar{w}=\gamma_{\min }$ and $d \Upsilon_{d} / d \bar{w}<0$ at $\bar{w}=w^{*}\left(\gamma_{\max }\right)$, there can only be one turning point of $\Upsilon_{d}$ in the middle range unless $d^{2} \Upsilon_{d} / d \bar{w}^{2}=0$ at least three times in this range. But, given that $G^{\prime}\left(\gamma^{*}(\bar{w})\right) /\left(1-G\left(\gamma^{*}(\bar{w})\right)\right.$ is increasing in $\bar{w}$, so also is $G\left(\gamma^{*}(\bar{w})\right) / G^{\prime}\left(\gamma^{*}(\bar{w})\right)$, while $(s+r)[\bar{w}(s-r)+r S] / 2 s^{2}$ is decreasing in $\bar{w}$. Therefore $d^{2} \Upsilon_{d} / d \bar{w}^{2}=0$ only once. It follows that $\Upsilon_{d}$ is concave in this range.

If $R / 2 \leq w^{*}\left(\gamma_{\min }\right), d \Upsilon_{d} / d \bar{w}<0$ for all $\bar{w} \in\left(w^{*}\left(\gamma_{\min }\right), w^{*}\left(\gamma_{\max }\right)\right]$. But we have seen that then $d E(\Upsilon) / d \bar{w}<0$ in the high range, while $\bar{w}$ should always be raised out of the low range. Therefore, if $R / 2 \leq w^{*}\left(\gamma_{\min }\right)$ it is optimal to set the $\bar{w}=w^{*}\left(\gamma_{\min }\right)$, i.e., in effect, there is no minimum wage.

Because $\epsilon_{d}^{L}\left(\gamma_{\min }\right)=\epsilon_{d}^{L}\left(\gamma_{\max }\right)=0$, if $R / 2 \in\left(w^{*}\left(\gamma_{\min }\right), w^{*}\left(\gamma_{\max }\right)\right)$ then $d \Upsilon_{d} / d \bar{w}>0$ at $\bar{w}=\gamma_{\min }$ and $d \Upsilon_{d} / d \bar{w}<0$ at $\bar{w}=$ $W^{*}\left(\gamma_{\max }\right)$. Therefore a solution interior to the middle range, $\bar{w} \in\left(W^{*}\left(\gamma_{\min }\right), w^{*}\left(\gamma_{\max }\right)\right)$ obtains. Since then $\epsilon_{d}^{L}\left(\gamma^{*}(\bar{w})\right)<0$, for $d \Upsilon_{d} / d \bar{w}=0$ it is necessary that $\bar{w}<R / 2$, while if $R / 2=w^{*}\left(\gamma_{\max }\right)$ we have that $d \Upsilon_{d} / d \bar{w}=0$ at $\bar{w}=w^{*}\left(\gamma_{\max }\right)$. Since the s.o.c. is satisfied the proposition follows.

Proof of Lemma 2. If $\alpha>s / 2(r+s)$ and $\gamma_{\max }>\gamma_{0}, \hat{w}(\alpha)<w^{*}\left(\gamma_{\max }\right)$, which is inconsistent with the range $\bar{w}>w^{*}\left(\gamma_{\max }\right)$, while $d \Omega_{l}(\gamma) / d \bar{w}<0$ for $\bar{w}>w^{*}\left(\gamma_{\max }\right)$. But when $\gamma_{\max }<\gamma_{0}$ and $\alpha>s /(r+s), \hat{w}(\alpha)$ is a well-defined maximum, consistent with $\bar{w}>w^{*}\left(\gamma_{\max }\right)$. To ensure that $\hat{w}(\alpha)<R+\gamma_{\min }$ it is necessary that $\gamma_{\min }>\gamma_{1}$.

Proof of Proposition 5. We first derive the f.o.c. for $\bar{w} \in\left[w^{*}\left(\gamma_{\min }\right), w^{*}\left(\gamma_{\max }\right)\right]$. Using (14), the first term in (15) can be written

$$
\int_{\gamma^{*}(\bar{w})}^{\gamma_{\max }} \Omega\left(I^{*}(\gamma)\right) g(\gamma) d \gamma=\frac{s\left[\left(1-G\left(\gamma^{*}(\bar{W})\right)\right)(R-S)^{2}+2 \epsilon_{d}^{H}\left(\gamma^{*}(\bar{W})\right)(R-S)+\sigma_{d}^{H}\left(\gamma^{*}(\bar{w})\right)\right]}{2(r+s)^{2}} .
$$

Using (4), the second term in (15) can be written

$$
\begin{aligned}
& \int_{\gamma_{\min }}^{\gamma^{*}(\bar{w})} \Omega_{l}(\gamma) g(\gamma) d \gamma=\frac{1}{2 r^{2}}(R-\bar{w})[2 \alpha r(\bar{w}-S)+(1-2 \alpha) s(R-\bar{w})] G\left(\gamma^{*}(\bar{W})\right) \\
& +\frac{1}{2 r^{2}}\left\{[2 \alpha r(\bar{w}-S)+2(1-2 \alpha) s(R-\bar{w})] \epsilon_{d}^{L}\left(\gamma^{*}(\bar{w})\right)+(1-2 \alpha) S \sigma_{d}^{L}\left(\gamma^{*}(\bar{w})\right)\right\},
\end{aligned}
$$

where $\epsilon_{d}^{L}\left(\gamma^{*}(\bar{w})\right)=\int_{\gamma_{\min }}^{\gamma^{*}(\bar{w})} \gamma g(\gamma) d \gamma$ and $\sigma_{d}^{L}\left(\gamma^{*}(\bar{w})\right)=\int_{\gamma_{\min }}^{\gamma^{*}(\bar{w})} \gamma^{2} g(\gamma) d \gamma$. 
Substituting these expressions into (15) and using (12), we obtain

$$
\begin{aligned}
& \frac{d \Omega_{d}}{d \bar{w}}=\frac{1}{r^{2}}[\alpha(2 s+r)-s] \epsilon_{d}^{L}\left(\gamma^{*}(\bar{w})\right)+\frac{1}{r^{2}} G\left(\gamma^{*}(\bar{w})\right)\{(R-\bar{w})[\alpha(r+2 s)-s]-\alpha r(\bar{w}-S)\} ; \\
& \frac{d^{2} \Omega_{d}}{d \bar{w}^{2}}=-\frac{1}{r^{2}} G\left(\gamma^{*}(\bar{w})\right)[2 \alpha(s+r)-s]+\frac{1}{r^{2} s^{2}}(\bar{w}-S) r(r+s)[\alpha(r+s)-s] G^{\prime}\left(\gamma^{*}(\bar{w})\right) .
\end{aligned}
$$

As $\epsilon_{d}^{L}\left(\gamma_{\min }\right)=G\left(\gamma_{\min }\right)=0, w^{*}\left(\gamma_{\min }\right)$ satisfies the f.o.c. (18) for $\bar{w} \in\left[w^{*}\left(\gamma_{\min }\right), w^{*}\left(\gamma_{\max }\right)\right]$. However, if $\alpha>s /(s+r), w^{*}\left(\gamma_{\min }\right)$ gives a local minimum because the objective function is convex at this point. Therefore, $\Omega_{d}$ is decreasing in $\bar{w}$ as it approaches $W^{*}\left(\gamma_{\min }\right)$ from above, whereas, using (12) and (18), iff $\gamma_{\max } \geq \gamma_{0}, \Omega_{d}$ is decreasing at $w^{*}\left(\gamma_{\max }\right)$. Also, we have seen that all $\bar{w}<w^{*}\left(\gamma_{\min }\right)$ result in the same $\Omega_{d}$ as $\bar{w}=w^{*}\left(\gamma_{\min }\right)$, whereas, by Lemma 2 , if $\alpha>s /(s+r)$ and $\gamma_{\max } \geq \gamma_{0}$, there is no candidate $\bar{w}>w^{*}\left(\gamma_{\max }\right)$. Hence, if $\alpha>s /(s+r)$ and $\gamma_{\max } \geq \gamma_{0}$, the globally optimal $\bar{w}$ must belong to $\left(w^{*}\left(\gamma_{\min }\right), w^{*}\left(\gamma_{\max }\right)\right]$.

Also, for $\bar{w} \in\left(w^{*}\left(\gamma_{\min }\right), w^{*}\left(\gamma_{\max }\right)\right]$, if $\Omega_{d}$ has a unique inflexion point there is a unique optimal $\bar{w}$ in this range. A sufficient condition for this is that $d^{2} \Omega_{d} / d \bar{w}^{2}$ is strictly monotonic. When $\alpha>s /(s+r)$,

$$
\operatorname{sign} \frac{d^{2} \Omega_{d}}{d \bar{w}^{2}}=\operatorname{sign}\left[h_{g}\left(\gamma^{*}(\bar{w})\right)(R-\bar{w})-\Delta\right]
$$

where $\Delta=(2 \alpha(s+r)-s) s^{2} /(\alpha(s+r)-s) r(s+r)$ and $h_{g}\left(\gamma^{*}(\bar{w})\right)=G^{\prime}\left(\gamma^{*}(\bar{w})\right) /\left(1-G\left(\gamma^{*}(\bar{w})\right)\right)$, which, by assumption, is strictly increasing. Since $h_{g}\left(\gamma^{*}(\bar{w})\right)(R-\bar{w})$ is monotonic in $\bar{w}$ over this range, $h_{g}\left(\gamma^{*}(\bar{w})\right)(R-\bar{w})-\Delta=0$ has a unique solution and so the inflexion point is unique and $\Omega_{d}$ is single-peaked on $\bar{w} \in\left(w^{*}\left(\gamma_{\min }\right), w^{*}\left(\gamma_{\max }\right)\right]$.

If $\alpha>s /(s+r)$ but $\gamma_{\max }<\gamma_{0}, \Omega_{d}$ is increasing at $w^{*}\left(\gamma_{\max }\right)$. Provided $\Omega_{d}$ is single-peaked on $\bar{w} \in\left(w^{*}\left(\gamma_{\min }\right), w^{*}\left(\gamma_{\max }\right)\right]$, then, given Lemma $2, \bar{w}=\hat{w}(\alpha)$, as given by (8), is the global optimum.

From (18), $d \Omega_{d}(\hat{w}(\alpha)) / d \bar{w}=[\alpha(2 s+r)-s] \epsilon_{d}^{L}\left(\gamma^{*}(\hat{w}(\alpha))\right) / r^{2} \leq 0$. A parallel argument then follows that made for (17).

Proof of Proposition 6. From (16), $d \Omega_{d}\left(w^{*}\left(\gamma_{\min }\right)\right) / d \bar{w}=0$ and $d^{2} \Omega_{d}\left(w^{*}\left(\gamma_{\min }\right)\right) / d \bar{w}^{2}<0$, so that $w^{*}\left(\gamma_{\min }\right)$ is a local maximum on $\bar{w} \in\left[w^{*}\left(\gamma_{\min }\right), w^{*}\left(\gamma_{\max }\right)\right]$. Also, from Lemma $2, d E\left(\Omega_{l}(\gamma)\right) / d \bar{w}<0$ for all $\bar{w}>w^{*}\left(\gamma_{\max }\right)$. Finally, any $\bar{w} \leq w^{*}\left(\gamma_{\min }\right)$ does not bind, so gives the same outcome. Therefore $w^{*}\left(\gamma_{\min }\right)$ is a well-defined maximum on $\left[w^{*}\left(\gamma_{\min }\right), w^{*}\left(\gamma_{\max }\right)\right]$, and any $\bar{w}<w^{*}\left(\gamma_{\min }\right)$ yields the same outcome, whereas $\Omega_{d}$ is lower for $\bar{w}>w^{*}\left(\gamma_{\max }\right)$. This proves the result.

\section{ORCID}

John Bennett (iD http://orcid.org/0000-0002-9118-2158

\section{REFERENCES}

Allen, S. P. (1987). Taxes, redistribution, and the minimum wage: A theoretical analysis. Quarterly Journal of Economics, 102, 477-489.

Askenazy, P. (2003). Minimum wage, exports and growth. European Economic Review, 47, 147-164.

Balart, P. (2016). The increase in college premium and the decline in low-skill wages: A signaling story. Journal of Public Economic Theory, 18, 363-384.

Bloom, N. (2014). Fluctuations in uncertainty. Journal of Economic Perspectives, 28(2), 153-175

Boeri, T. (2012). Setting the minimum wage. Labour Economics, 19(3), 281-290.

Bulow, J., \& Klemperer, P. (2012). Regulated prices, rent seeking, and consumer surplus. Journal of Political Economy, 120, 160186.

Cahuc, P., Carcillo, S., \& Zylberberg, A. (2014). Labor economics. Cambridge, MA: MIT Press .

Cahuc, P., \& Laroque, G. (2014). Optimal taxation and monopsonistic labor market: Does monopsony justify the minimum wage? Journal of Public Economic Theory, 16, 259-273.

Cahuc, P., \& Michel, P. (1996). Minimum wage unemployment and growth. European Economic Review, 40, $1463-1482$.

Danziger, E., \& Danziger, L. (2015). A Pareto-improving minimum wage. Economica, 82(326), 236-252.

Danziger, L. (2009). The elasticity of labor demand and the minimum wage. Journal of Population Economics, 22, 757-772. 
Davis, L. W., \& Kilian, L. (2011). The allocative cost of price ceilings in the us residential market for natural gas. Journal of Political Economy, 119, 212-241.

Economides, G., \& Moutos, T. (2016). Can minimum wages raise workers' incomes in the long run? Journal of Public Economic Theory, 18, 961-978.

Fanti, L., \& Gori, L. (2011). On economic growth and minimum wages. Journal of Economics, 103, 59-82.

Freeman, R. B. (1996). The minimum wage as a redistributive tool. Economic Journal, 106(436), 639-649.

Glaeser, E. L., \& Luttmer, E. F. (2003). The misallocation of housing under rent control. American Economic Review, 93, 10271046.

Guesnerie, R., \& Roberts, K. (1987). Minimum wage legislation as a second best policy. European Economic Review, 31, 490-498.

IZA (2014). IZA Compact (March). Bonn, Germany: Institute for the Study of Labor.

Jung, P., \& Kuhn, M. (2014). Labour market institutions and worker flows: comparing Germany and the US. Economic Journal, 124(581), 1317-1342.

Lee, D., \& Saez, E. (2012). Optimal minimum wage policy in competitive labor markets. Journal of Public Economics, 96, 739-749.

Luttmer, E. F. (2007). Does the minimum wage cause inefficient rationing? BE Journal of Economic Analysis and Policy, 7(1), 1-42.

MaCurdy, T. (2015). How effective is the minimum wage at supporting the poor? Journal of Political Economy, 123, 495-545.

Marshall, A. (1920). Principles of economics (8th ed.). London, UK: Macmillan.

Neumark, D., Salas, J. I., \& Wascher, W. (2014). Revisiting the minimum wage-employment debate: Throwing out the baby with the bathwater? Industrial and Labor Relations Review, 67, 608-648.

OECD. (2015). Employment outlook 2015. Paris, France: OECD Publishing.

Portugal, P., \& Cardoso, A. R. (2006). Disentangling the minimum wage puzzle: An analysis of worker accessions and separations. Journal of the European Economic Association, 4, 988-1013.

Schlee, E. E. (2013). Surplus maximization and optimality. American Economic Review, 103, 2585-2611.

Schmitt, J. (2013). Why does the minimum wage have no discernible effect on employment? Center for Economic and Policy Research. CEPR Reports and Issue Briefs 2013-04. Available at http://cepr.net/publications/reports/.

Sobel, R. S. (1999). Theory and evidence on the political economy of the minimum wage. Journal of Political Economy, 107, 761785.

Weitzman, M. L. (1974). Prices vs. quantities. Review of Economic Studies, 41, 477-491.

How to cite this article: Bennett J, Chioveanu I. The optimal minimum wage with regulatory uncertainty. J Public Econ Theory. 2017; 19:1136-1153. https://doi.org/10.1111/jpet.12276 